Illinois State University

ISU ReD: Research and eData

Theses and Dissertations

4-16-2017

\title{
School Climate, Stigma by Association, and Adolescent Psychological Distress
}

Kathryn D. Ferdon

Illinois State University, ferdkd@gmail.com

Follow this and additional works at: https://ir.library.illinoisstate.edu/etd

Part of the Educational Psychology Commons, and the Psychology Commons

\section{Recommended Citation}

Ferdon, Kathryn D., "School Climate, Stigma by Association, and Adolescent Psychological Distress" (2017). Theses and Dissertations. 752.

https://ir.library.illinoisstate.edu/etd/752

This Thesis is brought to you for free and open access by ISU ReD: Research and eData. It has been accepted for inclusion in Theses and Dissertations by an authorized administrator of ISU ReD: Research and eData. For more information, please contact ISUReD@ilstu.edu. 


\title{
SCHOOL CLIMATE, STIGMA BY ASSOCIATION, AND ADOLESCENT PSYCHOLOGICAL DISTRESS
}

\author{
Kathryn D. Ferdon
}

\section{Pages}

This thesis reports the results of a research project that examined whether school climate has a moderating effect on the relation between Stigma-by-Association and psychological distress among adolescents in a rural Midwestern county.

KEYWORDS: Adolescent, High School, Mental Health, School Climate, Stigma, Stigma by Association 


\section{SCHOOL CLIMATE, STIGMA BY ASSOCIATION, AND ADOLESCENT PSYCHOLOGICAL DISTRESS}

KATHRYN D. FERDON

A Thesis Submitted in Partial Fulfillment of the Requirements for the Degree of

MASTER OF SCIENCE

Department of Psychology

ILLINOIS STATE UNIVERSITY 
(C) 2017 Kathryn D. Ferdon 


\section{SCHOOL CLIMATE, STIGMA BY ASSOCIATION, AND ADOLESCENT PSYCHOLOGICAL DISTRESS}

KATHRYN D. FERDON

COMMITTEE MEMBERS:

Adena B. Meyers, Co-Chair

Renée M. Tobin, Co-Chair

John B. Pryor 


\section{ACKNOWLEDGMENTS}

First and foremost, praise and thanks goes to my savior Jesus Christ for the many blessings undeservingly bestowed upon me.

I would like to thank John B. Pryor for helping me get my project started and for serving as an expert resource in Stigma by Association. I would also like to thank Reneé M. Tobin for her guidance and support on this project. Additionally, I would like to give a special thank you to Adena B. Meyers for her diligence and commitment to this project, and for encouraging me to persist through the challenges writing a thesis often presents. Aside from the wonderful people

listed above, I also need to thank my encouraging cohort members, family, and friends for being a source of support throughout the entire process.

K. D. F. 


\section{CONTENTS}

Page

ACKNOWLEDGMENTS

CONTENTS

CHAPTER

I. THE PROBLEM AND ITS BACKGROUND 1

II. REVIEW OF THE RELATED LITERATURE 5

Overview of Stigma and Stigma by Association $\quad 5$

$\begin{array}{ll}\text { Measuring Stigma by Association } & 7\end{array}$

Research on Stigma by Association $\quad 8$

Factors Associated with Stigma by Association $\quad 8$

Effects of Stigma by Association 11

$\begin{array}{ll}\text { Overview of School Climate } & 14\end{array}$

$\begin{array}{ll}\text { Measuring School Climate } & 14\end{array}$

$\begin{array}{ll}\text { Research on School Climate } & 15\end{array}$

School Climate and Stigma by Association $\quad 18$

$\begin{array}{ll}\text { The Current Study } & 20\end{array}$

$\begin{array}{ll}\text { Hypotheses } & 21\end{array}$

$\begin{array}{ll}\text { III. METHODOLOGY } & 22\end{array}$

$\begin{array}{ll}\text { Recruitment and Participants } & 22\end{array}$

$\begin{array}{ll}\text { Measures } & 22\end{array}$

Stigma by Association $\quad 22$

School Climate $\quad 23$

Mental Health Symptoms $\quad 23$

$\begin{array}{ll}\text { Procedure } & 24\end{array}$

IV. RESULTS 26

Descriptive Statistics $\quad 26$

Tests of Hypotheses $\quad 29$

Follow-Up and Exploratory Analyses 30 
Additional Regressions

V. CONCLUSIONS 33

Summary of Findings $\quad 33$

Implications $\quad 36$

Strengths and Limitations $\quad 39$

Directions for Future Research $\quad 40$

$\begin{array}{ll}\text { Conclusions } & 41\end{array}$

$\begin{array}{ll}\text { REFERENCES } & 43\end{array}$

APPENDIX A: TABLES

$\begin{array}{ll}\text { APPENDIX B: FIGURES } & 57\end{array}$ 


\section{CHAPTER I}

\section{THE PROBLEM AND ITS BACKGROUND}

Approximately $20 \%$ of US adolescents have a diagnosable mental health disorder (Kessler, Berglund, Demler, Jin, \& Walters, 2005). Among US adolescents between 12 and 17, $11.4 \%$ (2.8 million adolescents) reported at least one Major Depressive Episode within the last year according to the results from the 2014 National Survey on Drug Use and Health (U.S. Substance Abuse and Mental Health Administration, SAMHSA, 2014). Despite effective treatments available, many adults and adolescents eligible for mental health services do not seek treatment (Corrigan, 2004). Individuals who experience mental health problems not only experience symptoms and disabilities that result from these concerns, but also negative perceptions and treatment by others. Corrigan (2004) indicates there is a nonspecific label effect, suggesting that individuals labeled with a mental health concern, regardless of the diagnosis or level or disability, are stigmatized more severely than those with other health conditions. Therefore, stigma, a mark which identifies someone as discredited (Goffman, 1963), can significantly impact whether an individual decides to receive treatment for mental health concerns (Corrigan, 2004). Additionally, stigmatized individuals are susceptible to negative perceptions of themselves, experiencing more negative emotions than individuals who do not feel stigmatized (e.g., anger and hopelessness), as well as behaviorally withdrawing and avoiding others and concealing their stigmatizing condition (Corrigan \& Watson, 2002).

Experiencing stigma due to a stigmatizing health condition also leads to others treating the stigmatized individual differently. This treatment can include an increased physical distance between the individual and another person, awkward social interactions, and being advised to 
conceal their condition, which can lead to greater amounts of psychological distress compared to those who do not have a stigmatizing health condition (Stutterheim, Pryor, Bos, Hoogendiijk, Muris, \& Schaalma, 2009).

Just as those with a stigmatizing condition experience stigma, individuals affiliated with the individual, such as family members, friends, and acquaintances, experience various levels of stigma due to their association with the individual who has the condition. The stigma and devaluation experienced by the affiliated individual is referred to as stigma by association (SBA). Various factors contribute to how much SBA an individual experiences, including the nature of the relationship (e.g., family, friend, acquaintance) between the affiliated individual and the individual with a stigmatizing condition, the type of mental health concern the stigmatized individual is experiencing, and other demographic variables, such as educational attainment and socioeconomic status (SES; Angermeyer, Link, \& Majcher-Angermeyer, 1987; Phelan, Bromet, \& Link, 1998; Pryor, Reeder, \& Monroe, 2012).

Stigmatizing reactions of others have been shown to negatively affect mental well-being, social life, and social networks of people affiliated with individuals with stigmatizing conditions (Van der Sanden, Stutterheim, Pryor, Kok, \& Bos, 2014). Individuals experiencing SBA tend to conceal their relationship with the stigmatized person or avoid the stigmatized person and others (Ostman \& Kjellin, 2002; Van der Sanden, Bos, Stutterheim, Pryor, \& Kok, 2015). In particular, research has shown affiliated individuals worry about losing potential relationships and friendships with others due to their relationship with the stigmatized individual (Van der Sanden et al., 2015). Further, social isolation and avoidance of others leave affiliated individuals susceptible to psychological symptoms and distress. Research has found that among affiliated individuals, those experiencing greater amounts of SBA have increased levels of anxiety, 
depression, suicidal thoughts, and withdrawal (Van der Sanden, Bos, Stutterheim, Pryor, \& Kok, 2013; Stutterheim et al., 2009).

Just as SBA leads to a host of mental health concerns, a negative school climate also leads to similar outcomes. School Climate is a construct that measures the quality and character of school life, and has been used to understand young people's perceptions regarding the social, emotional, and academic environment of their schools (National School Climate Center, 2015). Children and adolescents benefit from a positive school climate, as evidenced by lower levels of drug use (LaRusso, Romer, \& Selman, 2008), greater positive self-concept (Reynolds, Jones, Leger, \& Murgatroyd, 1980), and decreased student absenteeism (Gottfredson \& Gottfredson, 1989). Conversely, a less positive school climate has consistently been related to psychological distress and psychiatric problems (Kasen, Johnson, \& Cohen, 1990; LaRusso, Rormer, \& Selman, 2008; Ruus, Veisson, Leino, Ots, Pallas, Sarv, \& Veisson, 2007; Shochet, Dadds, Ham, \& Montague, 2006). More specifically, students who perceive a negative school climate are at an elevated risk for mental health concerns including internalizing and externalizing symptoms (Kuperminc, Leadbeater, \& Blatt, 2001, Shochet et al., 2006).

Given that both school climate and SBA have been linked to mental health difficulties, it is plausible that the negative experiences related to SBA may be influenced by school climate. Contextual variables, such as socioeconomic status (SES), have been connected to how much SBA an individual experiences. Affiliated individuals who are from higher SES backgrounds are more likely to conceal their relationship with the patient and avoid others than are individuals from lower SES backgrounds (Phelan et al., 1998). Individuals from high SES may feel as if they have more status or reputation to lose by knowing someone with a stigmatizing condition. Given that peer-based social hierarchies exist within the school setting, individuals who know someone 
with a stigmatizing condition may experience more judgment from others. In turn, they may feel they have more reputation to lose, similar to individuals from high SES backgrounds. This situation can lead to the perception of negative downward social comparison, in which affiliated individuals see the downward comparison as having negative implications for themselves (Buunk, Collins, Taylor, VanYperen, \& Dankof, 1990). Affiliated individuals who are in safe and relationally connected schools, however, may experience reduced feelings of SBA.

The present study aims to address gaps in the literature by investigating the effects of SBA on psychological distress among rural high school youth who report knowing someone with a stigmatizing condition. Additionally, the moderating effects of school climate on the association between SBA and psychological distress will be examined. Archival data collected from 115 students across three high schools in a Midwestern county will be analyzed. Perceptions of SBA will be examined as predictors of psychological distress among high school participants. Students' perceptions of SBA were assessed with an abbreviated and adapted version of the Stigma-by-Association Scale (Pryor, et. al, 2012), which measures cognitive, affective, and behavioral elements of SBA. Additionally, the amount of social support the respondent provided to the affiliated person with a mental health condition was assessed. To examine psychological distress, the Pediatric Symptom Checklist- Youth Report (Y-PSC; Jellinenk, Murphy, Robinson, Feins, Lamb, \& Fenton, 1988) was selected. Furthermore, school climate was examined as a moderating variable. School Climate and its four subscales will be examined, including Safety, Relationships, Teaching and Learning, and the Institutional Environment (Thapa, Cohen, Guffey, \& Higgins-D’Alessandro, 2013). 


\section{CHAPTER II}

\section{REVIEW OF THE RELATED LITERATURE \\ Overview of Stigma and Stigma by Association}

Goffman (1963) originally defined stigma as a mark that distinguishes someone as discredited. This distinction could include people marked by their skin color (race or ethnicity), physiology (gender), body size (obesity), clothes (poverty), and mental health conditions (Larson \& Corrigan, 2008; Corrigan et al., 2000). Stigma is conceptualized as a set of prejudicial attitudes (i.e., cognitive reactions), stereotypes (i.e., emotional reactions), and discriminatory behaviors (i.e., behavioral reactions; Corrigan, 2004). These thoughts, feelings, and behaviors must be endorsed by a biased social structure and a sizeable group toward a smaller discredited subgroup of people.

In addition to studying the public perception of those with stigmatizing conditions, researchers have considered stigmatized individuals themselves (Fife \& Wright, 2000; Mak et al., 2007). Research has consistently demonstrated individuals with stigmatizing conditions are more likely to experience psychological effects than the larger, public group (Bambauer \& Prigerson, 2006; Fife \& Wright, 2000; Mak et al., 2007). This experience is referred to as selfstigma, the process by which individuals with stigmatizing conditions internalize public groups' negative views toward themselves (Bos, Pryor, Reeder, \& Stutterheim, 2013). Through this internalization process, stigmatized individuals develop negative perceptions of themselves, experience more negative emotions (e.g., anger and 
hopelessness), behaviorally withdraw and avoid others, as well as conceal their stigmatizing condition (Corrigan \& Watson, 2002).

Similar to disease, stigma can spread from one person to another who is in some way associated with the person who has a stigmatizing condition. Family, friends, and even casual acquaintances can experience some of the stigma and devaluation from knowing someone with a stigmatizing condition. Thus, stigmatization includes three participants within the interaction: an individual with a stigmatizing condition, an affiliated individual, and the other who perceives them. Stigma by association examines affiliated individuals and their beliefs about how others perceive them due to their association with a stigmatized individual. Stigma by association (SBA), then, is the process through which the companions of stigmatized persons are discredited (Pryor, Reeder, \& Monroe, 2012). SBA has also been referred to as affiliate stigma and courtesy stigma (Larson \& Corrigan, 2008; Goffman 1963).

Like direct stigma, SBA comprises emotional, cognitive, and behavioral reactions (Pryor, Bos, Reeder, Stutterheim, Willems, \& McClelland, 2012). These three dimensions are common reactions when relatives or other social associates have a stigmatizing condition. Emotional reactions relate to the individual's personal feelings about having a relationship with the stigmatized individual, including feelings of disgust, anger, anxiety, or embarrassment. Cognitive reactions, in contrast, target personal beliefs of the associated individual, including how they would perceive others' reactions to their association with the stigmatized individual. These reactions can include the perception that others will engage in avoidance and exclusion toward the associated companion if they were aware of the companion's affiliation. Lastly, behavioral reactions include how the person associated with the stigmatized individual reacts physically to their affiliation. These behaviors might include gossiping to others about people 
with the stigmatizing condition, trying to keep the affiliation a secret, and avoidance of the person with the stigmatized condition. Pryor and colleagues (2012) found that experiences of SBA are also strongly related to perceived public stigma (i.e., societal reactions to people with the stigmatizing condition). Similar to self-stigma, research consistently suggests that individuals affiliated with someone who has a stigmatizing condition (SBA) are more likely to experience mental health symptoms of their own (Mak \& Kwok, 2010).

\section{Measuring Stigma by Association}

Research in the Stigma by association literature has examined the phenomenon from one of two primary perspectives. In some studies, researchers examine the affiliated individual, whereas other researchers study public perceptions of the affiliated individual. Research with affiliated individuals reveals the perceptions they have about how others may treat them based on their association with a stigmatized person. Studying public perceptions toward people who know a stigmatized person, however, provides more objective evidence about the perceptions affiliated individuals report. Within in the SBA literature, mental illnesses are often used as the original stigmatizing condition to identify affiliated individuals for the study (Mak \& Cheung, 2008; Ostman \& Kjellin, 2002; Phelan et al., 1998; van der Sanden et al., 2013). For instance, Ostman and Kjellin (2002) asked family members and non-relatives of patients with various DSM-IV diagnoses in acute psychiatric wards about their cognitions, emotions, and behaviors due to their association with an individual who has a mental illness.

Studies have used mixed methodology to understand the theoretical predictors and outcomes associated with SBA. Some have used semi-structured interviews to gain more qualitative information regarding the experiences of SBA among affiliated individuals (Ostman \& Kjellin, 2002; van der Sanden et al., 2014; van der Sanden et al., 2015). Other research has 
used more quantitative approaches (e.g., regression analyses), such as measures evaluating affiliated individuals' perceptions of others and others perceptions of affiliated individuals, to examine these relations (Mak et al., 2008; Phelan et al., 1998; Pryor et al., 2012; van der Sanden et al., 2013).

\section{Research on Stigma by Association}

\section{Factors Associated with Stigma by Association}

According to the research literature, a variety of indicators predict whether someone will be more likely to experience stigma by association, including physical and emotional proximity to the stigmatized individual, the type and severity of the stigmatizing condition, perceived burden, demographics (i.e., gender, SES), and cultural views about mental illnesses (Phelan et al., 1998). Research examining predictive factors of SBA are reviewed in the following sections.

Type of relationship (closeness). Pryor and colleagues (2012) examined whether the type of relationship (meaningful relationships vs. coincidental companions) of the stigmatized individual to the affiliated individual had an effect on the attitudes toward the associated individuals. Undergraduate students were shown a picture of a man with either an overweight female or a thin female, and the relationship was depicted as either arbitrary people together or as a meaningful relationship. Students were then asked to rate the attractiveness of the associated individual (i.e., the man). Follow up measures evaluated stigma-relevant attitudes using adaptations of the Affective Misattribution Procedure. Findings showed that participants with implicit negative weight-related attitudes devalued the companions of overweight women regardless of whether the relationship was coincidental or meaningful relationships. Participants with explicit negative weight-related attitudes also engaged in greater amounts of SBA when relationships were meaningful. Therefore, individuals in meaningful relationships with a 
stigmatized other are likely to experience more severe SBA than individuals in arbitrary relationships.

Additionally, Van der Sanden and colleagues (2013) evaluated the relation between SBA and outcome factors, such as perceived closeness. The study included 527 family members of people with a mental illness (e.g. schizophrenia, depressive disorders, addiction, ADHD). Four scales were used to assess the relations between SBA (Stigma by Association Scale) and perceived closeness (a single item inclusion of other), public stigma (i.e., the anticipated reactions of others; Public Stigma Scale), and psychological distress (Mental Health Inventory). Results indicated that the type of family relationship moderated these associations. With immediate family members, SBA was significantly and negatively related to perceived closeness. Alternatively, SBA was not significantly related to perceived closeness among extended family. These findings support the idea that relationship type (i.e., immediate vs. extended family) plays a role in how much SBA a family member experiences. More specifically, closely associated individuals (i.e., immediate family members), were more likely than distal associated individuals (i.e., extended family members) to report lower perceived closeness with the stigmatized individual. These researchers also found that perceived heredity of mental illness was not associated with the level of SBA experienced. Therefore, family members experienced similar levels of SBA regardless of whether the mental illness was perceived as hereditary.

Nature of stigmatizing condition. Despite the finding that perceived heredity does not influence SBA, other characteristics of the mental illness do play a role in the amount of SBA experienced. Phelan, Bromet, and Link (1998) examined parents and spouses of first-admission psychiatric patients with various DSM-III diagnoses. The number of psychotic symptoms 
experienced affected the amount of social avoidance family members engaged in. More specifically, family members related to patients with more baseline psychotic symptoms reported more avoidance of others. Positive symptoms of psychosis can be particularly stigma inducing because they are incomprehensible, disturbing, and frightening, and correspond most closely with public perception of mental illness. Consequently, the severity of the condition, or perceived danger may play a role in the severity of SBA someone experiences. In contrast, if the patient had more severe baseline positive or negative symptoms, there was less concealment as a result. Researchers suggest that severe symptomology will make it more difficult for close family members to conceal the problem. Thus, the urgent needs and demands may be more important in determining the extent of disclosure than family members' reasons to conceal information (e.g., the perceived stigma attached with the mental health condition).

Burden. Although not a direct effect of SBA, among affiliated individuals experiencing SBA, reports of perceived burden are widespread (Mak \& Cheung, 2008; Ostman \& Kjellin, 2002; Sanden et al., 2015). Burdens refer to the negative psychological feelings one has towards the individual with a stigmatizing condition (Mak \& Cheung, 2008). Burdens can be both objective (e.g., instability in routine and daily tasks, quarrels among family members) and subjective (e.g., exhaustion, emotional instability, guilt, anger, helplessness, loneliness) in affiliated individuals (Sanden et al., 2015). Specifically, affiliated individuals in caregiving positions report perceptions of burden and strain in caregiving. Subjective burdens among affiliated individuals, including caregivers, demonstrate increased stress levels as well as more negative attitudes toward caring for the stigmatized individual (Mak \& Cheung, 2008). Negative perceptions may be attributed to experiencing SBA, which could distort their views towards caregiving and the stigmatized individual in their care (Mak \& Cheung, 2008). Negative attitudes 
toward the stigmatized individual as a result of this perceived burden could have internalizing effects, and lead to psychological distress among those who are associated with someone who has a stigmatizing condition.

Demographic variables. Phelan and colleagues (1998) examined demographic variables, such as socioeconomic status (SES) and educational attainment. Results indicated that those with higher educational attainment and better occupational status were more likely to conceal their relationship with the patient. Additionally, participants who had greater levels of educational attainment were more likely to experience high rates of avoidance. Other studies have indicated that members of higher socioeconomic statuses (SES) experience greater levels of concealment (Angermeyer et al., 1987; Freeman \& Simmons, 1961). Individuals from high SES backgrounds may feel they have more status or reputation to lose by having mental illness in the family. Phelan and colleagues (1998) also examined patient gender, finding that relatives of female patients were more likely than relatives of male patients to conceal the relationship with the stigmatized person.

\section{Effects of Stigma by Association}

Concealment. When individuals feel devalued due to their connection to someone with a stigmatizing condition, associated behavioral tendencies have been observed. Stigmatizing reactions have been shown to affect mental well-being, social life, and social networks (Van der Sanden, et al., 2014). One way individuals react to the experience of SBA is to conceal their relationship with the stigmatized person or avoid the stigmatized person and others. Ostman and Kjellin (2002) examined 162 relatives of patients in acute psychiatric wards following both voluntary and compulsory admissions in Sweden. The study included spouses, parents, children, as well as other relatives (e.g., siblings), and non-relatives of patients who had various DSM-IV 
diagnoses. Researchers interviewed family members about different aspects of their experience, including the need for support and participation in the care for the patient. Levels of concealment (e.g., whether they invite guests to their homes), perceived closeness, and cognitions of the relative were assessed as well as the relative's symptomology. Results indicated that when the family member lived with the patient who had the mental illness, they were less likely to have company over. Therefore, living with a person with mental health concerns increases the likelihood of concealing the relationship with that person, and this in turn can lead to social isolation.

Avoidance. Other studies have used semi-structured interviews to examine the effects of SBA. Van der Sanden and colleagues (2015) studied 23 immediate family members of people with mental illnesses. Stigmatized individuals had broad diagnoses, including various mood disorders, personality disorders, ADHD, dissociative disorder, autism spectrum disorder, schizophrenia, or addiction. Researchers evaluated SBA and perceived burdens, and examined the extent to which these factors affected participants' experiences and well-being, as well as how they coped with these challenges. With this modest sample, several immediate family members reported avoiding social events, and reducing or breaking contact with family, friends, and acquaintances to avoid awkward questions and remarks about their family member. Family members also feared potential stigmatizing reactions and the loss of relationships and friendships of potential romantic partners due to their relationship with the stigmatized individual. Thus, family members of an individual with a mental illness were likely to avoid others.

Reasons for avoidance is further supported through qualitative reports in which family members indicated they were blamed for the onset or continuation of the mental illness by others (Van der Sanden, et al., 2015). The family member of an individual with a mental illness would 
explain the mental health condition to another individual, such as another family member, and the individual would respond with comments stating that the associated family member was the cause of the mental health problem. Situations such as these are aversive interactions, and lead to an avoidance of others as an escape from interactions where blame is put on the person experiencing SBA.

When people alienate themselves from others, including the stigmatized person as well as other family, friends, and acquaintances, to avoid association or further stigmatization, feelings of social exclusion arise. Van der Sanden and colleagues (2015) found that family members perceived more negative treatment from others (including mental health professionals), as well as exclusion by others. In addition, Van der Sanden and colleagues (2015) found decreased peer relationship quality and strained peer relationships among people affected by SBA. Individuals who experience these feelings of isolation and loneliness more often experience further negative outcomes, such as increased levels of psychological distress (Jackson \& Cochran, 1991).

Psychological distress. Individuals who know someone with a stigmatizing condition and are experiencing strained peer relationships as well as social exclusion, are susceptible to experience both SBA and psychological symptoms of their own. Individuals experiencing SBA have increased levels of anxiety, depression, suicidal thoughts, and withdrawal (van der Sanden et. al., 2013; Stutterheim et. al., 2009). Ostman and Kjellin (2002) found that relatives who felt the patient's mental illness had caused mental health problems in themselves experienced greater amounts of SBA and were more likely to have had suicidal thoughts than those who did not believe the cause of their mental health concerns were due to the patient's condition. Research should continue to examine SBA's effects on psychological distress because of other outcomes discussed within the literature (e.g. concealment, burden, avoidance). 


\section{Overview of School Climate}

School climate is a construct that measures the quality and character of school life, including students' perceptions regarding the social, emotional, and academic environment of their school (National School Climate Center, 2015). Some researchers propose a threedimensional view of school climate, including, social, academic, and physical factors (Character Education Partnership, CEP, 2013; Loukas, 2007). Other researchers suggest a four dimensional view of school climate consisting of safety (e.g. rules and norms, physical safety, socialemotional safety), relationships (e.g. respect for diversity, school connectedness/engagement, social support, leadership, and students' race/ethnicity and their perceptions of school climate), teaching and learning (e.g. social, emotional, ethical, and civic learning; service learning; support for academic learning; support for professional relationships; teachers and students' perceptions of school climate), and the external environment (e.g. physical surrounding, resources, supplies) (Cohen, McCabe, Michelli, \& Pickeral, 2009). Furthermore, some definitions of school climate may include a fifth dimension, such as leadership and professional relationships (NSCC, 2015) or the School Improvement Process (Thapa et al., 2013). Most researchers agree, however, that school climate is a multifaceted construct that comprises social, academic, and physical factors (CEP, 2013; Cohen, McCabe, Michelli, \& Pickeral, 2009; Collins \& Parsons, 2010; Hopson \& Lawson, 2011; Loukas, 2007; NSCC, 2012).

\section{Measuring School Climate}

The effects of school climate on student outcomes have been studied using a variety of methods. Both the subjective and objective aspects of school climate have been examined, in which subjective experiences refer to the experience of school, whereas objective aspects of school climate refer to the actual state of the school. However, most researchers agree school 
climate is a collection of individuals' perceived experiences that can be measured using subjective measures (Cohen, 2006; Cohen et al., 2009). When using subjective measures, as compared to objective measures (e.g., teacher qualifications, school building features), studies have found stronger relations between school climate and various outcomes (Kuperminc, Leadbeater, Emmons, \& Blatt, 1997). Still, subsequent research suggests that objective organizational changes in school climate (e.g., resources, teacher qualifications) can influence subjective perceptions (Kuperminc, et al., 2001). Overall, it is well understood that future research should examine the potential relationship between the subjective and objective aspects of school climate to determine interactions and discrepancies (Way, Reddy, \& Rhodes, 2007).

School climate perceptions are influenced by students' individual characteristics, which result in within-school variability in perceived climate (Loukas, 2007). Research has shown both individual-level characteristics and school-level climate influence various student outcomes (e.g., Brand, Felner, Shim, Seitsinger, \& Dumas, 2003; Koth, Bradshaw, \& Leaf, 2008; Suldo, McMahan, Chappel, \& Loker, 2012). Examining school climate across levels can help identify students who are at risk for harmful outcomes as well as recognize areas for school improvement. Therefore, it is beneficial to examine school climate at multiple contextual levels.

\section{Research on School Climate}

Both positive and negative outcomes have been observed in school climate research. The literature regarding positive perceptions of school climate shows links to many promising outcomes, such as fewer instances of bullying (Thapa et al., 2013), lower levels of drug use (LaRusso et al., 2008), decreased student absenteeism (Gottfredson \& Gottfredson, 1989), and greater positive self-concept and self-esteem (Hoge, Smith, \& Hanson, 1990; Reynolds et al., 1980). Kasen, Johnson, and Cohen (1990) found that positive perceptions of school climate were 
associated with reduced levels of emotional and behavioral problems. Other research has demonstrated negative correlations between school connectedness and mental health symptoms, including general functioning, depression, and anxiety symptoms (Shochet et al., 2006). More specifically, negative school climate perceptions have repeatedly been shown to be related to psychological distress and psychiatric problems (Kasen et al., 1990; LaRusso, Rormer, \& Selman, 2007; Ruus et. al., 2007; Shochet et al., 2006).

Internalizing/externalizing problems. When examining individual differences in vulnerability to psychopathology and school climate, lower levels of internalizing and externalizing problems have been associated with more positive school climate perceptions and lower psychological vulnerability. Kuperminc, Leadbeater, and Blatt (2001) examined middle school students' perceptions of school climate and internalizing/externalizing problems. Results showed that students with positive school climate perceptions reported lower levels of internalizing and externalizing problems. In contrast, those who had negative perceptions of school climate reported more experiences of self-criticism as well as more externalizing problems.

Teacher-student relationships. Other studies have examined teacher regard for students' perspectives as a part of the relationships dimension of school climate and depressive symptoms (LaRusso et al., 2007). Students reported a negative association between their perception of teacher regard/support and depressive symptoms. Therefore, students who had better perceived relationships with their teachers experienced less depressive symptomology.

School connectedness. Alternatively, Shochet and colleagues (2006) examined school connectedness and mental health symptoms over one year. The mental health symptoms they measured included depressive symptoms, hyperactivity, emotional symptoms, conduct problems, 
peer problems, and anxiety symptoms, as well as prosocial activities. The time measurements (between time 1 and time 2) of school connectedness remained fairly similar, indicating that school membership was stable over time. In addition, participants who reported more school connectedness also indicated less future depressive and anxiety symptoms for both boys and girls. Even after accounting for mental health symptoms, individual school connectedness predicted future depression, anxiety, and general functioning. These findings support the negative relation between favorable school climate and future mental health concerns.

Protective factors. Since school climate and psychological symptoms are closely related, it is relevant to explore coping strategies in relation to school climate as a protective factor. Ruus and colleagues (2007) asked 3,838 middle and high school students across 65 Estonian schools to report their coping strategies, psychological well-being, and school climate. Measures of coping focused on the formation of the coping strategies. Students were asked to evaluate their psychological and physiological well-being at school. Additionally, students rated their perceptions of school climate using Moos' three dimensions of human relations (1976), including questions about personality traits, maintence of status quo, and innovation. Results showed that students who used more constructive coping strategies were more likely to have greater school-related future optimism, psychological and physiological well-being, and academic success. It is important to note the students' relations with peers did not relate as strongly to coping or to other school climate parameters.

Overall, researchers have consistently demonstrated links between school climate and student outcomes. Although school climate has been conceptualized with various dimensions, the present study will focus on four dimensions of school climate (relationships, teaching and 
learning, safety, and the external environment) and their influence students' social-emotional and behavioral outcomes.

\section{School Climate and Stigma by Association}

Although favorable school climate has consistently been negatively correlated with various psychological symptoms and distress, such as anxiety, depression, and general functioning (Shochet et al., 2006), no current research has attempted to link how views on school climate may influence the extent to which an affiliated individual experiences stigma by association (SBA). For example, if the interpersonal climate in the school is favorable, students may be more likely to report they believe other students in their school view those with a stigmatizing condition as trustworthy, able to think clearly, and are safe. Thus, the favorable school climate would decrease the amount of Stigma by Association (SBA) reported among affiliated individuals.

Contextual variables, such as socioeconomic status (SES), are also a factor in determining how much SBA an individual experiences. As denoted in the study by Phelan and colleagues (1998), affiliated individuals who had higher educational attainment, occupational status, and SES were more likely to conceal their relationship with the patient. Affiliated participants who had greater levels of educational attainment were also likely to experience high rates of avoidance by others. Other studies indicated that members from higher socioeconomic statuses (SES), as compared to individuals from low SES, are more likely to conceal their relationship with the stigmatized individual (Angermeyer et al., 1987; Freeman \& Simmons, 1961). Individuals from high SES may feel they have more status or reputation to lose by having mental illness in the family. 
Just as individuals with high SES appear to have a status or reputation at stake, students in schools may also have similar feelings about keeping the status quo. Social relationships, cliques, and the formation of in-groups and out-groups begin at the preschool age (Aboud, 2003), and continue to form as a child develops. Most notably in middle and high school settings, there are social hierarchies in which students prefer certain students over others (Tringo, 1970). Although there is little research to my knowledge that addresses social hierarchies and other contextual variables in relation to SBA and school climate, it is possible that within these social hierarchies, students in preferred groups would in seek to maintain their social status or preference. If an adolescent student is from a social group of high status, they may feel as though they have more status or reputation to lose by knowing someone with a mental illness.

As previously mentioned, stigma strongly affects friends and family surrounding the stigmatized individual. Affiliation with stigmatized individuals can lead to serious problems, including psychological symptoms and mental health concerns. When examining SBA in the school setting, it is important to examine the effect school climate can have on individuals experiencing SBA. Improving school climate with respect to students' feelings of safety and connectedness at school could help decrease the degree of SBA that students who are affiliated with individuals with disabilities experience. In the context of a favorable school climate, one might anticipate that students affiliated with stigmatized individuals would be less likely to conceal these relationships, and would engage in less avoidance of others. Furthermore, since research has demonstrated those who experience SBA have increased levels of anxiety, depression, suicidal thoughts, and withdrawal, improving perceptions of school climate may assist in decreasing the psychological stress affiliated students experience. 
Understanding the effects of school climate on SBA could positively influence how schools function and the supports they provide to their students. Ultimately, it may be possible to help increase overall psychological well-being among high school students by further understanding and exploring the combined effects between stigma by association and school climate.

\section{The Current Study}

Previous research suggests that the severity of SBA influences the psychological distress experienced by the affiliated individual. Furthermore, due to social hierarchies that exist within a school, perceptions of school climate are likely to moderate the association between SBA and psychological distress. The present study, therefore, examines whether school climate, as measured by four of the five dimensions outlined by Thapa and colleagues (2013; i.e., Safety, Relationships, Teaching and Learning, and the Institutional Environment), moderates the association between SBA and psychological distress.

This study is unique in that the responders are adolescents within a rural school setting. Past researchers have primarily examined SBA in adults, and the construct has not yet been extended to children and adolescents to my knowledge. This study is also novel in that it is the first to focus on SBA within educational and rural settings. Additionally, it is the first time SBA will be examined in conjunction with school climate measures. There is currently a need to understand not only the experience of SBA itself, but factors that could reduce the negative effects associated with SBA. This study aims to add to this body of research, and will examine the role of school climate as a protective factor among adolescents in a rural Midwestern county. 


\section{Hypotheses}

The following hypotheses will be tested.

1. Does SBA predict psychological distress in students who are affiliated with an individual with a stigmatizing condition?

a. Students who experience more SBA will also experience greater psychological distress (Van der Sanden et. al., 2013; Stutterheim et. al., 2009).

2. Do students' perceptions of school climate predict their psychological distress?

a. Students who perceive more negative views of school climate will experience greater amounts of psychological distress (Shochet et al., 2006).

3. Does school climate moderate the relation between SBA and psychological distress?

a. An interaction is predicted between SBA, school climate, and psychological distress, such that there would be a stronger negative correlation between SBA and psychological distress when school climate is perceived as poor. Alternatively, when school climate is perceived as positive, a weaker correlation is expected between SBA and psychological distress, indicating less psychological distress among affiliated individuals. 


\section{CHAPTER III}

\section{METHODOLOGY}

\section{Recruitment and Participants}

School principals from high schools in a rural Midwestern county were contacted to be a part of the present study. For participating schools, trained researchers recruited participants for the research study at school events, such as informational meetings and registration. Researchers recruited both new and returning high school students to participate. The researchers explained the purpose of the study and obtained parental consent at these events. Adolescent participants later completed assent forms when they participated in the study. Data were collected from 115 high school students from 3 high schools in a geographically large rural county, with 89 students (77\%) who knew someone with a stigmatizing condition (e.g., ADHD, depression, anxiety, Autism Spectrum Disorder).

A total of 89 participants were included in the present study. Among the students who reported demographic information, there were 39 female and 43 male participants. These participants included 7 ninth grade students and 76 tenth grade students attending one of three high schools in a rural Midwestern county. The majority of participants were Caucasian (86\%).

\section{Measures}

\section{Stigma by Association}

Participants completed abbreviated and adapted versions of the Stigma-by-Association (SBA) Scale (Pryor et. al., 2012) and the Public Stigma Scale. For the SBA Scale (15 items; $\alpha=.96$ ), students answered two free response questions in which they listed their relationship to the individual (e.g., family member, friend, acquaintance) as well as the condition (e.g., depression, anxiety). Additionally, the scale measures students' cognitive, emotional, and 
behavioral reactions to being associated with someone with a stigmatizing condition. On each item of the Public Stigma Scale ( 7 items; $\alpha=.95$ ), students were asked to rate the degree to which they thought other students in their school would react to someone with a psychological condition or mental health problem. A measure of social support ( 5 items; $\alpha=.93$ ) was included to examine the level of social support respondents provided to individuals with stigmatizing conditions. Responses were rated on a 5-point scale ranging from 1 (strongly disagree) to 5 (strongly agree) for all SBA and Public Stigma measures.

\section{School Climate}

Participants completed a school climate survey using questions taken from and/or adapted from three different sources, including five items from the School Supportiveness subscale from the Sense of School Community Scale (Developmental Studies Center, 2005), 17 items created by researchers based on the 12 dimensions of school climate (National School Climate Center, n.d.), and 14 items from the Chicago Students as Allies Survey. The school climate scale included 36 questions on a 4-point Likert scale ranging from 0 (strongly disagree) to 4 (strongly agree). High scores on the school climate measure are indicative of more positive school climate perceptions. Reliability analyses from the current study were conducted to measure the internal consistency of school climate ( 36 items; $\alpha=.96$ ), and its four major dimensions including safety ( 9 items; $\alpha=.84$ ), relationships (13 items; $\alpha=.93$ ), teaching and learning ( 8 items; $\alpha=.88$ ), and the institutional environment ( 6 items; $\alpha=.84$ ).

\section{Mental Health Symptoms}

Participants completed the Pediatric Symptom Checklist- Youth Report (Y-PSC; Jellinek et al., 1988) ${ }^{1}$. The Y-PSC (35 items; $\alpha=.92$ ) is a self-report assessment tool used to evaluate cognitive, emotional, and behavioral concerns in children. Participants were asked to what 
degree the statement described themselves. Students indicated one of three response options: never, sometimes, or often. Two points were given for symptoms rated as "often," one point for “sometimes," and zero points for "never." Higher scores indicated greater frequencies and presence of that behavior. Items from the Y-PSC comprise three subscales: attention, internalizing problems, and externalizing problems. The Y-PSC will be used as a continuous to determine signs of significant symptoms and problems in attention, anxiety, depression, and conduct as well as overall significant psychological impairment. Jellinek and colleagues (1988) found that the overall test-retest reliability for the PSC ranges between $r=.84-.91$.

\section{Procedure}

Respondents completed a packet containing the school climate survey, SBA measure, and the Y-PSC during 30- to 60-minute research sessions. Participants sat at tables with space between each of them to reduce the likelihood that others would be able to see their responses. Trained researchers passed out packets in a manila folder, and read a script aloud to obtain assent from the participants. Researchers encouraged participants to ask questions prior to assenting. Students 18 or older provided their consent to participate in the study, and students 17 and under signed their name and dated the form to assent to the study. Students who did not wish to complete the forms were allowed to return to their classroom. Researchers informed students that if they had questions, they could raise their hand and a researcher would go over to them to answer their question.

Surveys included the adapted school climate scales, the Psychological Symptoms Checklist-Youth Report ${ }^{1}$ (Y-PSC; Jellinek et. al., 1988), and adapted versions of the Public

${ }^{1}$ Reprinted from Journal of Pediatrics, 112, Jellinek, M.S., Murphy, J.M., Robinson, J., Feins, A., Lamb, S., \& Fenton, T., The pediatric symptom checklist: screening school-age children for psychosocial dysfunction, 201-209, Copyright (1988). 
Stigma Scale and the Stigma-by-Association (SBA) Scale (Pryor et. al., 2012). The order of the questionnaires was counterbalanced to allow for the assessment of order effects.

Once students had completed the survey, participants brought their completed survey packets to the researcher enclosed in the manila envelope. Researchers then debriefed students individually or in small groups. Students were encouraged to ask questions, and the researchers provided students with contact information if they had any additional questions or concerns. After debriefing, students returned to their classrooms. 


\section{CHAPTER IV}

\section{RESULTS}

Data were collected between Fall of 2014 - Fall of 2015 from students attending one of three high schools in a rural Midwestern county. The modified school climate scale and the Stigma by Association (SBA) scale along with its corresponding subscales were the predictor variables, with the Psychological Symptoms Checklist- Youth Report (Y-PSC) and corresponding subscales were the primary outcome variables for hypotheses one and two. Crossproduct regression was used to test the third hypothesis, with the school climate scale serving as a moderating variable, with the SBA scale as the predictor variable, and the Y-PSC scale scores as the outcome variables. Multiple linear regressions were run in addition to hierarchical linear regressions through SPSS to investigate the interaction effects between school climate, SBA, and psychological distress.

The results will be presented in four sections. First, descriptive statistics on the various measures and correlational analyses will be presented. In section 2, the results for hypotheses 1 through 3 will be presented, as outlined in Chapter 2. Finally, in section 3, follow-up and exploratory analyses will be discussed.

\section{Descriptive Statistics}

The present study included 115 high school students from 3 schools in a geographically large rural county, with 89 students (77\%) who knew someone with a stigmatizing condition. Table A-1 lists the frequencies and percentages of participants' reports on demographic data, 
including sex, race, and grade. As can be seen, the sample primarily consisted of White $9^{\text {th }}$ and $10^{\text {th }}$ grade students.

Frequency counts were conducted for both relationship and condition type. Table A-2 lists participant responses regarding their relationship to a stigmatized individual and the stigmatized individuals' condition(s) among the 89 students who reported knowing someone with a stigmatizing condition. Of the 89 students who reported knowing someone with a stigmatizing condition, the most frequently reported conditions were depression (28\%) and ADHD (15\%). Furthermore, 18\% of students reported knowing someone with comorbid conditions. The most frequent co-occurring conditions were depression and anxiety. A total of 10 condition types emerged, varying in severity and nature (i.e., depression, anxiety, ADHD, Autism Spectrum Disorder, Bipolar disorder, addiction, eating disorder, neuro-genetic disorder, academic concerns, and other). Additionally, according to the data, students most often reported knowing a friend or best friend with a stigmatizing condition (59\%), compared to a family member $(17 \%)$. It is important to note 9 people reported knowing more than one individual with a stigmatizing condition.

A one-way ANOVA was conducted to examine the differences between the affiliated individual's relationship type and reports of Stigma by Association. Results yielded significant differences between the relationship type reported and social support, indicating that closer relationships lead to greater social support, $F(10,79)=3.66, p=.001$. Social Support means were significantly higher for both family (i.e., extended and immediate family) and friendships (i.e., Best Friend and Friend) as compared to acquaintances. Specifically, Immediate Family had an average Social Support score of $4.66(S D=.67)$, Extended Family $4.36(S D=.67)$, Best Friend 
$4.66(S D=.47)$, Friend $4.14(S D=.93)$, and Acquaintances $3.15(S D=.1 .2)$. Overall reports of SBA did not significantly differ as a function of the relationship type reported.

Additionally, preliminary correlational analyses were conducted, as denoted in Table A-3, between Stigma by Association (SBA), School Climate, and Psychological Distress, as well as other variables included in the SBA measure (i.e., Public Stigma and Social Support). Correlational analyses revealed that overall School Climate was negatively associated with psychological distress $(r=-.24 ; p<.05)$. Furthermore, SBA was significantly related to both Public Stigma $(r=.64 ; p<.01)$ and Social Support $(r=-.51 ; p<.01)$. Results indicate that when affiliated individuals believe that other students at school are less accepting toward people with mental health concerns, affiliated individuals experience greater SBA. Affiliated individuals will also provide less social support to an individual with mental health concerns when perceived SBA is greater. It is important to note that all measures (i.e., School Climate, SBA, and Psychological Distress) were found to be highly reliable. Refer to Table A-4 for a full list of descriptive statistics.

One way ANOVA's were conducted to screen for significant differences between the three schools. Results indicated that schools were significantly different in regards to perceptions of Safety, but were not significantly different when examining the overall School Climate Scale or other subscales (i.e., External Environment, Relationships, and Teaching and Learning). Specifically, School 1 obtained an average Safety Scale score of $2.30(S D=.32)$, where as School 2 obtained a score of $1.99(S D=.52)$, and School 3 obtained a score of $1.70(S D=.57)$. These Safety Scale scores, therefore, were significantly different, $F(2,87)=3.55, \mathrm{p}=.03$. Other measures (i.e., Stigma by Association, Psychological Distress) yielded nonsignificant results between the three schools included in the sample. 


\section{Tests of Hypotheses}

1. The first hypothesis predicted that students who experience more SBA will also experience greater psychological distress (Van der Sanden et. al., 2013; Stutterheim et. al., 2009). Correlations were conducted to examine the association between SBA and Psychological Distress, which yielded nonsignificant results $(r=.07, p=.54)$. Thus, the hypothesis was not supported.

2. Hypothesis 2 predicted that students who perceive more negative views of school climate will experience greater amounts of psychological distress (Shochet et al., 2006). As mentioned previously, a significant negative relationship was found between School Climate and Psychological Distress $(r=-.24 ; p<.05)$. A linear regression was then calculated to predict Psychological Distress based on School Climate. This model was significant $[\mathrm{F}(1,76)=4.56, p=.04]$, with an $\mathrm{R}^{2}$ of .06 . Therefore, School Climate was a significant predictor of Psychological Distress, and the hypothesis was supported.

3. Hypothesis 3 predicted an interaction between SBA, school climate, and psychological distress, such that there would be a stronger negative correlation between SBA and psychological distress when school climate is perceived as poor. Alternatively, when school climate is perceived as positive, a weaker correlation is expected between SBA and psychological distress, indicating less psychological distress among affiliated individuals. Refer to Table A-5 for data outcomes. Hierarchical Regression analyses were run to test whether School Climate moderated the relation between SBA and Psychological Distress. In the first step (see table 3), SBA was not a significant predictor of Psychological Distress $[\mathrm{F}(1,76)=.379, p=.54]$, with an $\mathrm{R}^{2}$ of .01 . School Climate was entered in the second step, yielding significant findings $[\mathrm{F}(2,76)=2.717, p=.03]$, 
with an $\mathrm{R}^{2}$ of .07 . Main effect results indicate that while SBA does not significantly predict Psychological Distress, reports of School Climate do significantly predict Psychological Distress. Therefore, if school climate is perceived as unfavorable, students will experience greater mental health symptoms. In the third step, a cross product of SBA and School Climate was added to examine interaction effects. Results indicated that School Climate significantly moderated the relation between SBA and Psychological Distress $[\mathrm{F}(3,76)=3.38, p=.04]$, with an $\mathrm{R}^{2}$ of .12 . Thus, the hypothesis was supported. A simple slopes analysis illustrated in Figure B-1 delineates the significant moderating effects of school climate on the relationship between SBA and psychological distress. When school climate is perceived as positive, individuals with SBA experience minimal amounts of psychological distress. Alternatively, when school climate is unfavorable, individuals with SBA experience greater amounts of psychological distress.

Interestingly, although SBA was nonsignificant when main effects were examined alone, SBA emerged as a significant predictor when the interaction term was entered into the model.

\section{Follow-Up and Exploratory Analyses}

\section{Additional Regressions}

Additional regressions were examined to delineate the moderating effects of School Climate on the relationship between Stigma by Association (SBA) and Psychological Distress. Specifically, the four areas of School Climate were analyzed, including Relationships, Teaching and Learning, Safety, and the External Environment. The Relationship dimension was divided into two sub-dimensions, including teacher to student relationships and student to student relationships. All dimensions were substituted with school climate in the hierarchical regression seen under hypothesis 3. Significant moderating relationships were found for the following 
dimensions of School Climate: Student to Student Relationships $[\mathrm{F}(3,60)=5.80, p=.020$, $\left.\mathrm{R}^{2}=.23\right]$, Teaching and Learning $\left[\mathrm{F}(3,76)=2.62, p=.02, \mathrm{R}^{2}=.10\right]$, and Safety $[\mathrm{F}(3,76)=6.35, p$ $\left.=.018, \mathrm{R}^{2}=.21\right]$. Please refer to Tables A-6 to A-8 for full statistical findings. Results indicate these three factors as significant moderators between SBA and Psychological Distress. Alternatively, Relationships, Teacher to Student Relationships, and the External Environment were nonsignificant moderators independent of other School Climate dimensions.

\section{Hayes Process Model}

The relation between School Climate and Psychological Distress was examined, with Public Stigma and SBA as mediators using Hayes (2013) Process Model. The process model was selected to explore how School Climate interacts within a model of stigma conceptualized by Pryor and Reeder (2011), where unfavorable School Climate acts as structural stigma, or an institutional variable that exacerbates stigma. Hayes model number 6 was used to examine the mediating relations. Results, as depicted in Figure B-2, indicated insignificant mediating relationships between School Climate and Psychological distress, with Public Stigma and SBA as mediators. The significance of this indirect effect was examined using bootstrapping procedures. Unstandardized indirect effects were computed for each of the 5,000 bootstrapped samples and used a 95\% confidence interval. Although significant indirect effects were not found, through the same bootstrapping procedures, there were two statistically significant relationships in which School Climate predicted SBA $[b=.32, t(74)=2.30, p=.024]$ and Public Stigma predicted SBA $[b=.42, t(74)=7.47, p<.001]$.

Additionally, the relation between School Climate and Social Support was examined, with Public Stigma and SBA as mediators using Hayes (2013) Process Model. Model number 6 was used to examine the mediating relations. Results indicated that the association between School Climate and Social Support was mediated by SBA, but not Public Stigma. As Figure B-2 
illustrates, the standardized regression coefficient between School Climate and SBA was statistically significant $[b=.28, t(84)=.23, p<.001]$, as was the standardized regression coefficient between SBA and Social Support $[b=-.95, t(83)=.16, p<.001]$. The standardized indirect effect was -.27. The significance of this indirect effect was examined using bootstrapping procedures. Unstandardized indirect effects were computed for each of the 5,000 bootstrapped samples and used a 95\% confidence interval. The bootstrapped unstandardized indirect effect was .13 , and the $95 \%$ confidence interval ranged from -.59 to -.05 . Thus, the indirect effect was statistically significant. In addition, results indicated that Public Stigma significantly predicted the level of social support given to an individual with a stigmatizing condition $[b=.26, t(83)=2.44, p=.017]$, but was insignificant when examined as a mediator. 


\section{CHAPTER V}

\section{CONCLUSIONS}

\section{Summary of Findings}

While previous research has focused on the stigma individuals with a mental health condition experience, recent research has begun to explore Stigma by Association (SBA), or the process of devaluation affiliated individuals, such as family members, friends, and acquaintances, experience (Goffman, 1963). Similar to the effects of self-stigma, the stigmatizing reactions of others towards affiliated individuals can have a negative impact on mental well-being, social life, and social networks (Van der Sanden, Stutterheim, Pryor, Kok, \& Bos, 2014). Additionally, affiliated individuals experiencing SBA tend to conceal their relationship with the stigmatized person or avoid the stigmatized person and others (Ostman \& Kjellin, 2002; Van der Sanden, Bos, Stutterheim, Pryor, \& Kok, 2015), and demonstrate greater amounts of psychological symptoms, such as anxiety and depression (Van der Sanden, Bos, Stutterheim, Pryor, \& Kok, 2013; Stutterheim et al., 2009).

As mentioned before, research has primarily sought to understand the nature of SBA within adult populations and family relations. The present study examined the role of SBA within adolescent students and high school settings. As a result, School Climate was used to measure the affiliated individuals' perceptions regarding the social, emotional, and academic environment of their school. Previous research indicates that a positive school climate can reduce internalizing and externalizing problems among students (Kuperminc, Leadbeater, \& Blatt, 2001) as well as produce a host of other positive outcomes, such as fewer instances of bullying (Thapa et al., 2013) and greater positive self-concept and self-esteem (Hoge, Smith, \& Hanson, 1990; Reynolds et al., 1980). 
The purpose of the present study was to extend the Stigma by Association (SBA) and School Climate literature as well as guide educational practices that enhance affiliated individuals' mental well-being in high school settings. The current study examined the moderating effects of School Climate on the relation between Stigma by Association (SBA) and psychological distress. As a result, the following hypotheses were developed (1) students who experience more SBA will also experience greater psychological distress (Van der Sanden et. al., 2013; Stutterheim et. al., 2009); (2) students who perceive more negative views of school climate will experience greater amounts of psychological distress (Shochet et al., 2006); and (3) a significant interaction between SBA, school climate, and psychological distress, such that there would be a stronger negative correlation between SBA and psychological distress when school climate is perceived as poor. It was hypothesized that when school climate is favorable, the relationship between SBA and psychological distress would weaken, with school climate serving as a buffer or protective factor against mental health symptoms among students experiencing SBA. These hypotheses were investigated using cross-product regression, with the school climate scale serving as a moderating variable, with the SBA scale as the predictor variable, and the Y-PSC scale scores as the outcome variable. Additionally, multiple linear regressions were run through SPSS to investigate the interaction effects between school climate, SBA, and psychological distress. Across analyses, results provided partial support for hypotheses.

Sample average scores and standard deviations for both SBA and Public Stigma were compared to previous research. Although previous research has focused on familial relationships and adults to examine SBA, previous studies have reported higher averages of both SBA and Public Stigma than in the present study. Specifically, Van der Sanden et al. (2013), a study focusing on immediate and extended family relationships among adults, found that the mean 
SBA score was $1.93(S D=1.06)$. Comparatively, the present study had a lower mean SBA score of $1.41(S D=0.75$.). Similarly, the mean report of Public Stigma was 3.51 $(S D=0.48)$ in Van der Sanden et al. (2013), and an average score of $1.87(S D=1.10)$ in the current study. While measures of SBA and Public Stigma were modified and used on younger populations, it is important to note that students reported less SBA and Public Stigma than in previous studies.

Findings in the present study, however, revealed that although SBA did not significantly predict psychological distress, school climate did predict mental health symptoms among affiliated individuals. A significant negative relationship was found between School Climate and Psychological Distress. Students who reported favorable school climates also reported lower levels of psychological distress. Alternatively, students who reported unfavorable or more negative school climates reported greater levels of psychological distress. Additionally, School Climate was found to be a significant moderator between SBA and Psychological Distress. When school climate is unfavorable, individuals with SBA experience greater amounts of psychological distress. Follow-up analyses found that specific aspects of school climate (i.e., Student to Student Relationships, Teaching and Learning, and Safety) significantly moderated the relation between SBA and psychological distress, indicating specific aspects of school climate to target when seeking to reduce psychological symptoms among students experiencing SBA.

Interestingly, although SBA was not a significant predictor of symptoms when examined alone, it emerged as a significant predictor when the interaction term was entered into the model. In the full model, SBA positively predicted symptoms.

Exploratory analyses examined the relation between School Climate and Psychological Distress, with Public Stigma and SBA as mediators using the Hayes (2013) Process Model. The 
process model was selected to explore how School Climate fits within a model of stigma conceptualized by Pryor and Reeder (2011), where unfavorable School Climate acts as structural stigma, or an institutional variable that exacerbates stigma (Figure B-2). While results did not support this model, School Climate and Public Stigma independently predicted SBA. More specifically, if students report School Climate as unfavorable, students will report greater SBA. Similarly, if students report greater amounts of Public Stigma (i.e., the belief that people at school have negative perceptions and beliefs about mental health) affiliated individuals report greater amounts of Stigma by Association (SBA).

Additionally, the relation between School Climate and Social Support was examined, with Public Stigma and SBA as mediators using the Hayes (2013) Process Model (Figure B-3). While findings indicated that Public Stigma significantly predicted the level of social support given to an individual with a stigmatizing condition, SBA was the only significant mediator between School Climate and Social Support. Therefore, if school climate is unfavorable, affiliated individuals report greater SBA and then provide less social support back to the individual with a stigmatizing condition.

\section{Implications}

Follow-up analyses found that specific aspects of school climate (i.e., Student to Student Relationships, Teaching and Learning, and Safety) significantly moderated the relation between SBA and psychological distress, indicating specific aspects of school climate to target when seeking to reduce psychological symptoms among students experiencing SBA. The Student to Student Relationships component specifically measures the affiliated individual's perceptions of how well students like each other, if students are willing to go out of their way to help someone, if students work together to solve problems, and if students care about each other. Therefore, 
focusing on aspects of the interpersonal climate among peers and social support could greatly buffer against affiliated individuals' mental health symptoms. According to a research study completed by Higgins-D'Alessandro \& Sakwarawich (2011), students with stigmatizing conditions (i.e., Individual Education Plans; IEPs) were only able to benefit from positive school climate if they felt included and respected by other students, further supporting the critical role peer relationships play in the well-being of students with differences.

Additionally, Teaching and Learning refers to social, emotional, ethical, and civic learning, as well as support for academic learning and professional relationships. A positive school climate would foster the belief that students in the school care about learning and getting a good education, teachers are committed to teaching, students are being prepared for life after high school, and that students are being encouraged to develop their own voice. Adena and Hickey (2014) suggest that changes in school structure (i.e., referring to alterations in the teaching environment) as well as enhancing individual skill development using social and emotional learning curriculums(SEL) can lead to greater positive outcomes for children and a more favorable school climate. Alterations in school structure produce change in classrooms and school climate through interventions such as the Responsive Classroom and Caring School Community, where the environment targeted. Alternatively, skill development approaches, such as The Incredible Years and the 4Rs, target students' skills leading to a positive change in school climate. Therefore, targeting social and emotional learning (SEL) at both the environmental and individual level are examples of how to create a more positive Teaching and Learning environment.

Lastly, Safety, including physical as well as social-emotional safety, is imperative for schools to invest in when seeking to reduce mental health symptoms among affiliated 
individuals. Increasing feelings of safety include developing a fair discipline policy, having clear and fair rules, school personal enforcing rules fairly, and fostering a sense that students are safe from physical and social-emotional harm, including verbal abuse and teasing. Recent research has found that when threat assessment procedures are followed, students report less bullying, feel more comfortable seeking help, and possess more positive perceptions of school climate (Cornell \& Sheras, 2006). Additionally, research has shown that consistent enforcement of school discipline and availability of caring adults were associated with school safety (Gregory et al., 2010). Therefore, if teachers and other administrative personnel focus on creating clear rules and enforcing corrective procedures, students are more likely to feel more safe and students experiencing SBA will be less vulnerable to mental health symptoms.

Increasing positive views of student to student relationships, teaching and learning, and safety as well as overall School Climate could help buffer the effects Stigma by Association has on affiliated individuals in school settings (i.e., mental health concerns). School Climate research has recognized the need for improving school climate and school connectedness to reduce mental health concerns, such as depression and anxiety, as found in Shochet and colleagues' (2006) study explained in chapter II. While current research has sought to understand how to improve aspects of school climate, specific interventions targeting the reduction of Stigma by Association are needed.

As noted in the present study, views of public stigma predicted feelings of Stigma by Association (SBA). Students who believed others in their school and community were less accepting of individuals with mental health conditions reported greater feelings of SBA. To change students' and teachers' attitudes and beliefs about mental health within a school (i.e., Public Stigma), current research suggests educating others on mental illness, and providing 
opportunities for others to come into contact with people who have mental illness (Corrigan, Morris, Micheals, Rafacz \& Rüsch, 2012). According to a meta-analysis conducted by Corrigan and colleagues' (2012), interventions involving contact are more effective for adults, such as teachers and administrators, while education seems to work best among adolescents. Educating staff and students as well as coming into contact with individuals who have stigmatizing conditions can help to reduce negative views of mental illness, or the public perception of mental illness, ultimately reducing public stigma and feelings of SBA.

\section{Strengths and Limitations}

The current study is unique in that responders are adolescents within a rural school setting. Past researchers have primarily examined SBA in adults and family members, and the present study is the first to extend SBA to children and adolescents as well as peer relationships to our knowledge. This study is also novel in that it is the first to focus on SBA within educational and rural settings. Additionally, it is the first time SBA has been examined in conjunction with school climate measures.

The current study has some limitations within the findings that need to be interpreted carefully. Some limitations of this study should be mentioned. First, the present study's reliance on self-reported data is a possible limitation. While self-report data are economical and can measure constructs that would be too difficult to obtain with behavioral and physiological measures, relying on self-report could lead to some potential biases, including image management, a lack of introspective ability, as well as response bias. However, the potential bias that results from self-reported data was minimized insofar as was possible by assuring participants' data would be deidentified. 
Additionally, the present study did not distinguish whether the individual with a mental health condition had a diagnosed condition or a perceived mental health condition by the affiliated individual. Future research should seek to distinguish between symptoms of a mental health condition vs. diagnosed psychopathology when examining perceptions and effects of SBA. The present study was cross-sectional in nature and reflects the perceptions and feelings of participants at a single point in time and does not capture changes that may occur over time. Finally, while this sample does a good job of representing students within high schools in the rural Midwestern county sampled, this population is geographically restricted. In particular, racial minorities are underrepresented relative to the country as a whole, including African American, Hispanic, and Asian populations. Future research with larger, longitudinal samples representing more diverse groups of high school adolescents is recommended. Nevertheless, although, the sample size for the study was small, the findings indicate statistically significant trends that are worthy of future investigation.

\section{Directions for Future Research}

As mentioned above, future research should seek to distinguish between symptoms of a mental health condition vs. diagnosed psychopathology when examining effects of SBA. While it is possible that affiliated individuals' perceptions of a friend or family member's mental health symptoms are just as stigmatizing as a diagnosed condition, future research should seek to delineate these effects. As noted above, future research should examine these effects with larger and more diverse groups, using longitudinal samples.

Additionally, exploratory analyses examined whether school climate functions as an institutional stigma, as outlined by Pryor and Reeder (2011). Their definition of institutional stigma is the "perpetuation of a stigmatized status by society's institutions and ideological 
systems." Although these data do not support the idea that School Climate functions in this way, it is possible that School Climate serves as an outside buffer variable that protects individuals experiencing SBA from various negative outcomes, such as their own mental health concerns rather than as an institution that perpetuates stigma. More specifically, it is plausible that specific aspects of School Climate (i.e., Safety, Teaching and Learning, Student to Student Relationships) found in the present study protect affiliated individuals from mental health conditions of their own. Future research should continue to examine the role of School Climate within models of stigma, specifically with SBA and self-stigma in child and adolescent populations.

\section{Conclusions}

With one fifth of the US adolescent population diagnosed with a mental health disorder (Kessler, Berglund, Demler, Jin, \& Walters, 2005), there is a need to not only study individuals with mental health conditions (i.e., self-stigma), but the affiliated individuals surrounding the individual with a mental health concern (i.e., family, friends, and acquaintances experiencing Stigma by Association [SBA]). The present study found that school climate moderated the relation between SBA and psychological distress. Therefore, when school climate is favorable, the relation between SBA and psychological distress weakens, with school climate serving as a buffer or protective factor against mental health symptoms among students experiencing SBA. Targeting specific aspects of School Climate through intervention, education, and exposure that promote a sense that school is a safe place, students are accepting of others, and that school is a place for teaching and learning, can buffer the negative mental health effects of Stigma by Association (SBA). These findings, along with the finding that SBA serves as mediator between School Climate and social support demonstrate the need for future research on Stigma by 
Association in adolescent populations and high school contexts, as well as the effects of SBA on non-family members (e.g., friendships, acquaintances). 


\section{REFERENCES}

Aboud, F. E. (2003) The formation of in-group favoritism and out-group prejudice in young children: are they distinct attitudes? Developmental Psychology, 39(1), 48-60. http://dx.doi.org/10.1037/0012-1649.39.1.48

Angermeyer, M. C., Link, B. G., \& Majcher-Angermeyer, A. (1987). Stigma perceived by patients attending modern treatment settings: Some unanticipated effects of community psychiatry reforms. Journal of Nervous and Mental Disease, 175, 4-11. http://dx.doi.org.libproxy.lib.ilstu.edu/10.1097/00005053-198701000-00002

Bambauer, K. Z., \& Prigerson, H. G. (2006). The stigma receptivity scale and its association with mental health service use among bereaved older adults. The Journal of Nervous and Mental Disease, 194, 139-141. http://dx.doi.org.libproxy.lib.ilstu.edu/10.1097/01.nmd.0000198200.20936.03

Bos, A. E. R., Pryor, J. B., Reeder, G. D., \& Stutterheim, S. E. (2013) Stigma: advances in theory and research. Basic and Applied Social Psychology, 35, 1-9. doi: $10.1080 / 01973533.2012 .746147$

Brand, S., Felner, R., Shim, M., Seitsinger, A., \& Dumas, T. (2003). Middle school improvement and reform: development and validation of a school-level assessment of climate, cultural pluralism, and school safety. Journal of Educational Psychology, 95, 570-588. doi: $10.1037 / 0022-0663.95 .3 .57$

Buunk, B. P., Collins, R. L., Taylor, S. E., VanYperen, N. W., \& Dakof, G. A. (1990). The affective consequences of social comparison: either direction has its ups and downs. Journal of Personality and Social Psychology, 59, 1238-1249. http://dx.doi.org.libproxy.lib.ilstu.edu/10.1037/0022-3514.59.6.1238 
Character Education Partnership. (2013). School climate. Retrieved from http://www.character.org/key-topics/school-climate/.Cohen, J. (2006). Social, emotional, ethical, and academic education: Creating a climate for learning, participation in democracy, and well-being. Harvard Educational Review, 76, 201-237. doi: 10.17763/haer.76.2.j44854x1524644vn

Cohen, J., McCabe, E. M., Michelli, N. M., \& Pickeral, T. (2009). School climate: research, policy, practice, and teacher education. Teachers College Record, 111, 180-213.

Collins, T. N., \& Parsons, K. A. (2010). School climate and student outcomes. Journal of CrossDisciplinary Perspectives in Education, 3, 34-39.

Cornell, D., \& Sheras, P. (2006) Guidelines for responding to student threats of violence. Longmont, CO: Sopris West.

Corrigan, P. (2004). How stigma interferes with mental health care. American Psychologist 59, 614-625. http://dx.doi.org/10.1037/0003-066X.59.7.614

Corrigan, P. W., Morris, S. B., Michaels, P. J., Rafacz, J.D., \& Rüsch, N. (2012). Challenging the public stigma of mental illness: A meta-analysis of outcome studies. American Psychiatric Association, 63, 963-973. http://dx.doi.org/10.1176/appi.ps.201100529

Corrigan, P. W., River, L., Lundin, R. K., Wasowski, K. U., Campion, J., Mathisen J., et al. (2000). Stigmatizing attributions about mental illness. Journal of Community Psychology, 28, 91-102. http://dx.doi.org.libproxy.lib.ilstu.edu/10.1002/(SICI)15206629(200001)28:1<91::AID-JCOP9>3.0.CO;2-M

Corrigan, P. W., \& Watson, A. C. (2002). Understanding the impact of stigma on people with mental illness. World Journal of Psychiatry, 1, 16-19. 
Developmental Studies Center (2005). Scales from student questionnaire, child development project middle school student follow-up study (grades 6-8). Oakland, CA. Retrieved from http://www.devstu.org/sites/default/files/media/pdfs/cdp/DSC_MidSch_scales.pdf

Durlak, J. A., Weissberg, R. P., Dymnicki, A. B., Taylor, R. D., \& Schellinger, K. B. (2011) The impact of enhancing students' social and emotional learning: A meta-analysis of schoolbased universal interventions. Child Development, 82, 405-432. doi:

10.1111/j.1468624.2010.01564.x

Fife, B. L., \& Wright, E.R. (2000). The dimensionality of stigma: a comparison of its impact on the self of persons with HIV/AIDS and cancer. Journal of Health and Social Behavior, 41, 50-67. http://dx.doi.org.libproxy.lib.ilstu.edu/10.2307/2676360

Freeman, H. E, \& Simmons, O. G. (1961) Feelings of stigma among relatives of former mental patients. Social Problems, 8, 312-321.

Gregory, A., Cornell, D., Fan, X., Sheras, P., Shih, T., \& Huang, F. (2010) Authoritative school discipline: High school practices associated with lower student bullying and victimization. Journal of Educational Psycholog, 102, 483-496. doi: 10.1037/a0018562

Goffman, E. (1963). Stigma: notes on the management of spoiled. Englewood Cliffs, NJ: Prentice-Hall.

Gottfredson, G. D., \& Gottfredson, D. C. (1989) School climate, academic performance, attendance, and dropout. (ERIC Document Reproduction Service No. ED 308225)

Hedden S. L., Kennet, J., Lipari, R., Medley, G., \& Tice, P. (2015). Behavioral health trends in the united states: results from the 2014 national survey on drug use and health. U.S. Substance Abuse and Mental Health Administration, 1-37. 
Higgins-D’Alessandro, A., \& Sakwarawich, A. (2011, October). Congruency and determinants of teacher and student views of school culture. Paper presented at the Association for Moral Education annual conference, Nanjing, China.

Hoge, D. R., Smit, E. K., \& Hanson, S. L. (1990). School experiences predicting changes in selfesteem of sixth- and seventh-grade students. Journal of Educational Psychology, 82, 117127. doi:10.1037/0022-0663.82.1.117

Hopson, L. M., \& Lawson, H. (2011). Social workers' leadership for positive school climates via data informed decision-making. Children and Schools, 33), 106-118. http://dx.doi.org.libproxy.lib.ilstu.edu/10.1093/cs/33.2.106

Jackson, J., \& Cochran, S. D. (1991). Loneliness and psychological distress. Journal of Psychology, 125, 257-262. doi: 10.1080/00223980.1991.10543289

Jellinek, M. S., Murphy J. M., Robinson, J., Feins, A., Lamb, S., \& Fenton, T. (1988) The pediatric symptom checklist: screening school-age children for psychosocial dysfunction. Journal of Pediatrics, 112, 201-209. doi: 10.1016/S0022-3476(88)80056-8

Kasen, S., Johnson, J., \& Cohen, P. (1990). The impact of school emotional climate on student psychopathology. Journal of Abnormal Child Psychology, 18, 165-177. http://dx.doi.org.libproxy.lib.ilstu.edu/10.1007/BF00910728

Kessler, R. C., Berglund, P, Demler, O., Jin, R., \& Walters, E. E. (2005). Life-time prevalence and age-of-onset distribution of DSM-IV disorders in the national co-morbidity survey replication. Archives of General Psychiatry, 62, 593-602.

http://dx.doi.org/10.1001/archpsyc.62.7.768 
Koth, C. W., Bradshaw, C. P., \& Leaf, P. J. (2008). A multilevel study of predictors of student perceptions of school climate: The effect of classroom-level factors. Journal of Educational Psychology, 100, 96-104. http://dx.doi.org.libproxy.lib.ilstu.edu/10.1037/0022-0663.100.1.96

Kuperminc, G. P., Leadbeater, B. J., \& Blatt, S. J. (2001). School social climate and individual differences in vulnerability to psychopathology among middle school students. Journal of School Psychology, 39, 141-159. http://dx.doi.org.libproxy.lib.ilstu.edu/10.1016/S00224405(01)00059-0

Kuperminc, G.P., Leadbeater, B. J., Emmons, C., \& Blatt, S. J. (1997). Perceived school climate and difficulties in the social adjustment of middle school students. Applied Developmental Science, 1, 76-88. http://dx.doi.org.libproxy.lib.ilstu.edu/10.1207/s1532480xads0102_2

Larson, J. E., \& Corrigan, P. W. (2008). The stigma of families with mental illness. Academic Psychiatry, 32, 87-91. doi: 10.1176/appi.ap.32.2.87

LaRusso, M. D., Romer, D., \& Selman, R. L. (2007). Teachers as builders of respectful school climates: Implications for adolescent drug use norms and depressive symptoms in high school. Journal of Youth Adolescence, 37, 386-398. http://dx.doi.org.libproxy.lib.ilstu.edu/10.1007/s10964-007-9212-4

LaRusso, M. D., Romer, D., \& Selman, R. L. (2008). Teachers as builders of respectful school climates: implications for adolescent drug use norms and depressive symptoms in high school. Journal of Youth and Adolescence, 37, 386-398. http://dx.doi.org.libproxy.lib.ilstu.edu/10.1007/s10964-007-9212-4 
Loukas, A. (2007). What is school climate? Leadership Compass, 5(1). Retrieved from http://www.naesp.org/resources/2/Leadership_Compass/2007/LC2007v5n1a4.pdf.

Mak, W. W. S., \& Cheung, R. Y. M. (2008). Affiliate stigma among caregivers of people with intellectual disability or mental illness. Journal of Applied Research in Intellectual Disabilities, 21, 532-545. doi: 10.1111/j.1468-3148.2008.00426.x

Mak, W. W. S., Cheung, R. Y. M., Law, R. W., Woo, J., Li, P. C. K., \& Chung, R. (2007). Attribution model of self-stigma on social support and psychological well-being among people with HIV+/AIDS. Social Science and Medicine, 64, 1549-1559. http://dx.doi.org.libproxy.lib.ilstu.edu/10.1016/j.socscimed.2006.12.003

Mak, W. W. S. \& Kwok, Y. T. Y. (2010). Internalization of stigma for parents of children with autism spectrum disorder in Hong Kong. Social Science \& Medicine, 70, 2045-2051. http://dx.doi.org.libproxy.lib.ilstu.edu/10.1016/j.socscimed.2010.02.023

Meyers, A. B., \& Hickey, A. M. (2014). Multilevel prospective dynamics in school-based social and emotional learning programs. Journal of Cognitive Education \& Psychology, 13, $218-231$.

National School Climate Center (2015). School climate. Retrieved from http://schoolclimate.org/climate/.

Ostman, M., \& Kjellin, L. (2002) Stigma by association: psychological factors in relatives of people with mental illness. British Journal of Psychiatry, 181, 494-498. http://dx.doi.org.libproxy.lib.ilstu.edu/10.1192/bjp.181.6.494

Phelan, J. C., Bromet, E. J., \& Link, B. G. (1998). Psychiatric illness and family stigma. Schizophrenia Bulletin, 24, 115-126. http://dx.doi.org.libproxy.lib.ilstu.edu/10.1093/oxfordjournals.schbul.a033304 
Pryor, J. B., Bos, A. E. R., Reeder, G. D., Stutterheim, S. E., Willems, R. A., \& McClelland, S. (2012). Reactions to stigma-by-association: relationships to reduced psychological wellbeing, closeness to stigmatized relatives, and public stigma. Unpublished manuscript, Department of Psychology, Illinois State University, Normal, IL.

Pryor, J. B., Reeder, G. D., \& Monroe, A. E. (2012). The infection of bad company: Stigma by association. Journal of Personality and Social Psychology, 102, 224-241. http://dx.doi.org.libproxy.lib.ilstu.edu/10.1037/a0026270

Reynolds, D., Jones, D., Leger, S., \& Mutgatroyd, S. (1980). School factors and truancy. In I. Hersov \& I. Berg (Eds.), Out of school: Modern perspectives in truancy and school refusal (pp 85-110). Chicher, UK: John Wiley.

Russ, V. R., Veisson, M., Leino, M., Ots, L., Pallas, L., Sarv, E.S., \& Veisson, A. (2007) Students' well-being, coping, academic success, and school climate. Social Behavior and Personality, 35, 919-936. http://dx.doi.org.libproxy.lib.ilstu.edu/10.2224/sbp.2007.35.7.919

Shochet, I. M., Dadds, M. R., Ham, D., \& Montague, R. (2006) School connectedness is an underemphasized parameter in adolescent mental health: results of a community prediction study. Journal of Clinical Child and Adolescent Psychology, 35, 170-179. http://dx.doi.org.libproxy.lib.ilstu.edu/10.1207/s15374424jecp3502_1

Stutterheim, S. E., Pryor, J. B., Bos, A. E., Hoogendijk, R., Muris, P., \& Schaalma, H. P. (2009). HIV-related stigma and psychological distress: the harmful effects of specific stigma manifestations in various social settings. AIDS, 23, 2353-2357. http://dx.doi.org.libproxy.lib.ilstu.edu/10.1097/QAD.0b013e3283320dce 
Suldo, S. M., McMahan, M. M., Chappel, A. M., \& Loker, T. (2012). Relationships between perceived school climate and adolescent mental health across genders. School Mental Health, 4, 69-80. http://dx.doi.org.libproxy.lib.ilstu.edu/10.1007/s12310-012-9073-1

Thapa, J. C., Cohen, J., Guffey, S., \& Higgins-D’Alessandro, A. (2013) A review of school climate research. Review of Educational Research. 83, 357-385. http://dx.doi.org.libproxy.lib.ilstu.edu/10.3102/0034654313483907

Tringo, J. L. (1970). The hierarchy of preference toward disability groups. Journal of Special Education, 4, 295-306. http://dx.doi.org.libproxy.lib.ilstu.edu/10.1177/002246697000400306

Van der Sanden, R., Bos, A., Stutterheim, S. E., Pryor, J. B., \& Kok, G. (2013) Experiences of stigma by association among family members of people with mental illness. Rehabilitation Psychology, 58, 73-80. http://dx.doi.org/10.1037/a0031752

Van der Sanden, R., Bos, A., Stutterheim, S. E., Pryor, J. B., \& Kok, G. (2015) Stigma by association among family members of people with a mental illness: a qualitative analysis. Journal of Community \& Applied Social Psychology, 25, 400-417. http://dx.doi.org.libproxy.lib.ilstu.edu/10.1002/casp.2221

Van der Sanden, R., Stutterheim, S. E., Pryor, J. B., Kok, G., \& Bos, A. (2014) Coping with stigma by association and family burden among family members of people with mental illness. The Journal of Nervous and Mental Disease, 202), 710-717. http://dx.doi.org.libproxy.lib.ilstu.edu/10.1097/NMD.0000000000000189 
Way, N., Reddy, R., \& Rhodes, J. (2007). Students' perceptions of school climate during the middle school years: associations with trajectories of psychological and behavioral adjustment. American Journal of Community Psychology, 40, 194-213.

http://dx.doi.org.libproxy.lib.ilstu.edu/10.1007/s10464-007-9143-y 


\section{APPENDIX A: TABLES}

Table A-1. Demographics

Demographic Variable Frequency

$\%$

$\underline{\text { Sex }}$

Male

43

47.8

Female

39

43.3

$\underline{\text { Race }}$

African American

4

4.4

Native American

0

0

Hispanic

3

3.3

Asian American

0

0

Biracial/Multiethnic

1

White

73

1.1

Other

1

81.1

1.1

$\underline{\text { Grade }}$

$9^{\text {th }}$

7

7.8

$10^{\text {th }}$

76

84.4 
Table A-2. Stigma by association condition and relationship descriptions

Condition and Relationship

Condition

Depression

Anxiety

ADHD

ASD

Bipolar

Addiction

Eating Disorder

Neurogenetic Disorder

Academic Concerns

Other

Common Comorbid Conditions

Anxiety \& Depression

ADHD \& Academic Concerns

Frequency

25

8

13

10

2

1

0

3

7

4

4

7

2

7.8

2.2

Relationship

Immediate Family Member

$10 \quad 11.1$

Extended Family Member

Best Friend

$5 \quad 5.6$

Friend

15

16.7

Acquaintance

38

42.2

Self

13

14.4

Multiple Relationships

0

9

0

9.9

Table A-3. Relations among stigma by association, school climate, and psychological distress

\begin{tabular}{lccccc}
\hline & 1 & 2 & 3 & 4 & 5 \\
\hline 1. Stigma by Association & 1 & .16 & .07 & $-.51^{* *}$ & $.64^{* *}$ \\
2. School Climate & .16 & 1 & $-.24^{*}$ & .00 & -.08 \\
3. Psychological Distress & .07 & $-.24^{*}$ & 1 & .13 & -.16 \\
4. Social Support & $-.51^{* *}$ & .00 & .13 & 1 & -.16 \\
5. Public Stigma & $.64^{* *}$ & -.08 & -.16 & -.16 & 1 \\
\hline$* * p<.01, * p<.05$ & & & & &
\end{tabular}


Table A-4. Descriptive statistics

\begin{tabular}{lcccccc}
\hline Variable & $N$ & Mean & SD & Min & Max & $\alpha$ \\
\hline Stigma by Association & 88 & 1.41 & 0.75 & 1.00 & 5.00 & .96 \\
Public Stigma & 88 & 1.87 & 1.10 & 1.00 & 5.00 & .95 \\
Social Support & 88 & 4.20 & .97 & 1.00 & 5.00 & .93 \\
& & & & & & \\
School Climate & 90 & 1.91 & 0.51 & 0.50 & 2.91 & .94 \\
$\quad$ Safety & 90 & 2.01 & .52 & 0.67 & 3.00 & .82 \\
$\quad$ Teaching and Learning & 90 & 1.78 & .59 & 0.25 & 2.88 & .89 \\
$\quad$ Relationships & 74 & 1.83 & .59 & 0.31 & 3.00 & .93 \\
$\quad$ Institutional Environment & 74 & 1.97 & .58 & 0.00 & 3.00 & .83 \\
& & & & & & \\
Psychological Distress & 77 & .45 & 0.31 & 0.00 & 1.34 & .92 \\
\hline
\end{tabular}

Table A-5. Summary of hierarchical regression analyses for stigma by association and school climate predicting psychological symptoms

\begin{tabular}{lcccccc}
\hline Variables & $\beta$ & $\mathrm{t}$ & $R$ & $R^{2}$ & $\Delta R^{2}$ & $F$ \\
\hline Step 1 & & & .07 & .01 & .01 & $\mathrm{~F}(1,76)=.38, p=.54$ \\
$\quad$ Stigma by Association & .03 & .05 & & & & \\
$\quad$ Step 2 & & & .26 & .07 & .06 & $\mathrm{~F}(2,76)=2.72, p=.03$ \\
$\quad$ Stigma by Association & .05 & .94 & & & & \\
$\quad$ School Climate & -.17 & $-2.24^{*}$ & & & & \\
$\quad$ Step 3 & & & .35 & .12 & .05 & $\mathrm{~F}(3,76)=3.38, p=.04$ \\
$\quad$ Stigma by Association & .15 & $2.18^{*}$ & & & & \\
$\quad$ School Climate & -.17 & $-2.35^{*}$ & & & & \\
$\quad$ SBA x School Climate & -.23 & $-2.11^{*}$ & & & & \\
\hline$* * p<.01, * p<.05$ & & & & & &
\end{tabular}


Table A-6. Summary of hierarchical regression analyses for stigma by association and student to student relationships predicting psychological symptoms

\begin{tabular}{lcccccc}
\hline Variables & $\beta$ & $\mathrm{t}$ & $R$ & $R^{2}$ & $\Delta R^{2}$ & $F$ \\
\hline Step 1 & & & .06 & .00 & .00 & $\mathrm{~F}(1,60)=.18, p=.67$ \\
$\quad$ Stigma by Association & .06 & .43 & & & & \\
Step 2 & & & .40 & .16 & .15 & $\mathrm{~F}(2,60)=5.41, p=.002$ \\
$\quad$ Stigma by Association & .10 & .86 & & & & \\
$\quad$ Student to Student & -.40 & $-3.26^{* *}$ & & & & \\
$\quad$ Relationships & & & & & & \\
Step 3 & & & .48 & .23 & .08 & $\mathrm{~F}(3,60)=5.80, p=.02$ \\
$\quad$ Stigma by Association & .38 & $2.30^{*}$ & & & & \\
$\quad$ Student to Student & -.43 & $-3.62^{* *}$ & & & & \\
$\quad$ Relationships & & & & & & \\
$\quad$ SBA x Student to & -.39 & $-2.29^{*}$ & & & & \\
$\quad$ Student Relationships & & & & & & \\
\hline$* * p<.01, * p<.05$ & & & & & & \\
& & & & &
\end{tabular}

Table A-7. Summary of hierarchical regression analyses for stigma by association and teaching and learning predicting psychological symptoms

\begin{tabular}{lcccccc}
\hline Variables & $\beta$ & $\mathrm{t}$ & $R$ & $R^{2}$ & $\Delta R^{2}$ & $F$ \\
\hline Step 1 & & & .07 & .01 & .01 & $\mathrm{~F}(1,76)=.38, p=.54$ \\
$\quad$ Stigma by Association & .07 & .62 & & & & \\
Step 2 & & & .17 & .03 & .02 & $\mathrm{~F}(2,76)=1.06, p=.19$ \\
$\quad$ Stigma by Association & .10 & .85 & & & & \\
$\quad$ Teaching and Learning & -.15 & $-1.32^{* *}$ & & & & \\
Step 3 & & & .31 & .10 & .07 & $\mathrm{~F}(3,76)=2.62, p=.02$ \\
$\quad$ Stigma by Association & .38 & $2.33^{*}$ & & & & \\
$\quad$ Teaching and Learning & -.18 & $-1.56^{* *}$ & & & & \\
$\quad$ SBA x Teaching and & -.39 & $-.39^{*}$ & & & & \\
Learning & & & & & & \\
$* * p<.01, * p<.05$ & & & & & &
\end{tabular}


Table A-8. Summary of hierarchical regression analyses for stigma by association and safety predicting psychological symptoms

\begin{tabular}{lcccccc}
\hline Variables & $\beta$ & $\mathrm{t}$ & $R$ & $R^{2}$ & $\Delta R^{2}$ & $F$ \\
\hline Step 1 & & & .07 & .01 & .01 & $\mathrm{~F}(1,76)=.38, p=.54$ \\
$\quad$ Stigma by Association & .07 & .62 & & & & \\
$\quad$ Step 2 & & & .38 & .14 & .14 & $\mathrm{~F}(2,76)=6.20, p=.001$ \\
$\quad$ Stigma by Association & .08 & .76 & & & & \\
$\quad$ Safety & -.37 & $-3.45^{* *}$ & & & & \\
Step 3 & & & .46 & .21 & .06 & $\mathrm{~F}(3,76)=6.35, p=.018$ \\
$\quad$ Stigma by Association & .28 & $2.10^{*}$ & & & & \\
$\quad$ Safety & -.37 & $-3.58^{* *}$ & & & & \\
$\quad$ SBA x Safety & -.32 & $-2.42^{*}$ & & & & \\
\hline
\end{tabular}




\section{APPENDIX B: FIGURES}

Figure B-1. Simple slope analysis

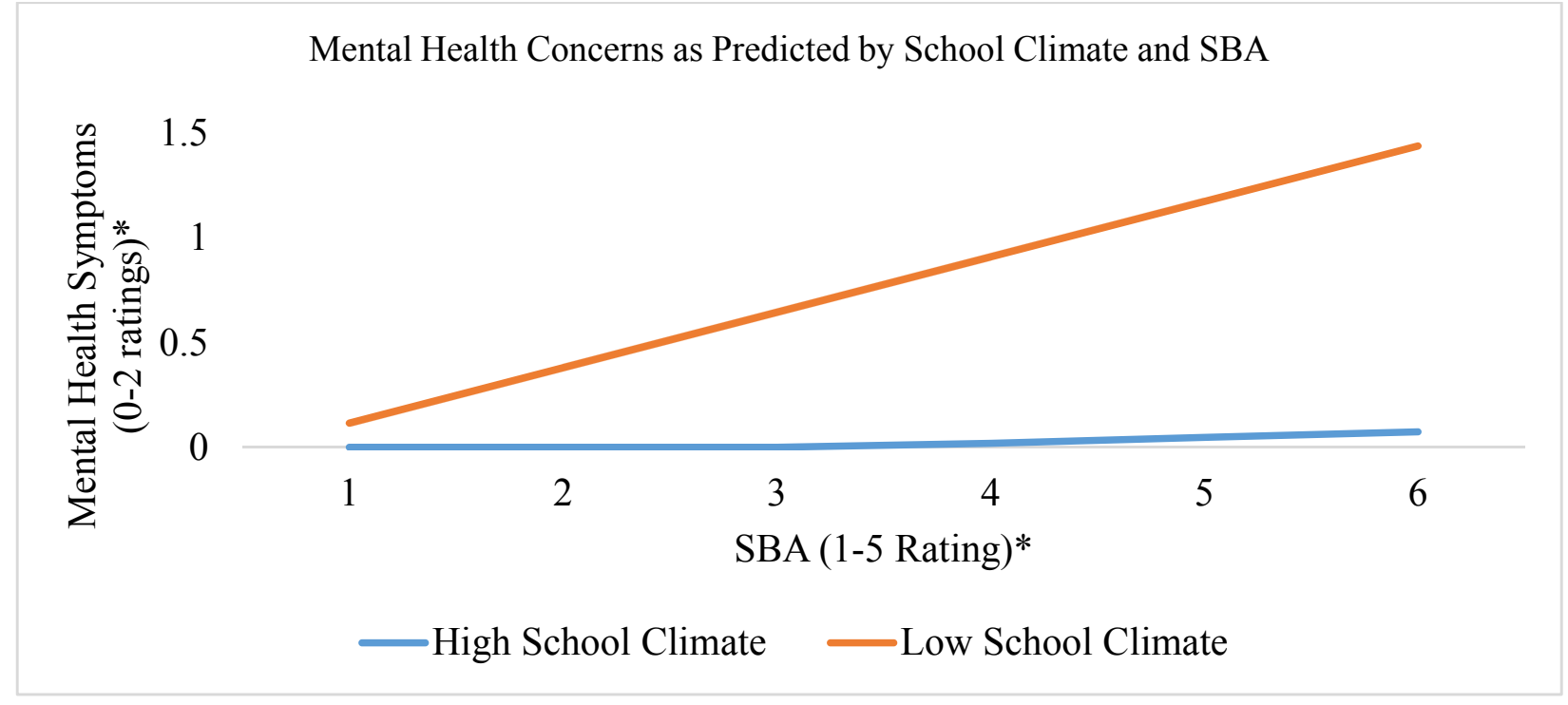

*Higher ratings $=$ greater mental health symptoms/SBA

Figure B-2. Hayes process model of public stigma and stigma by association mediating school climate and psychological distress

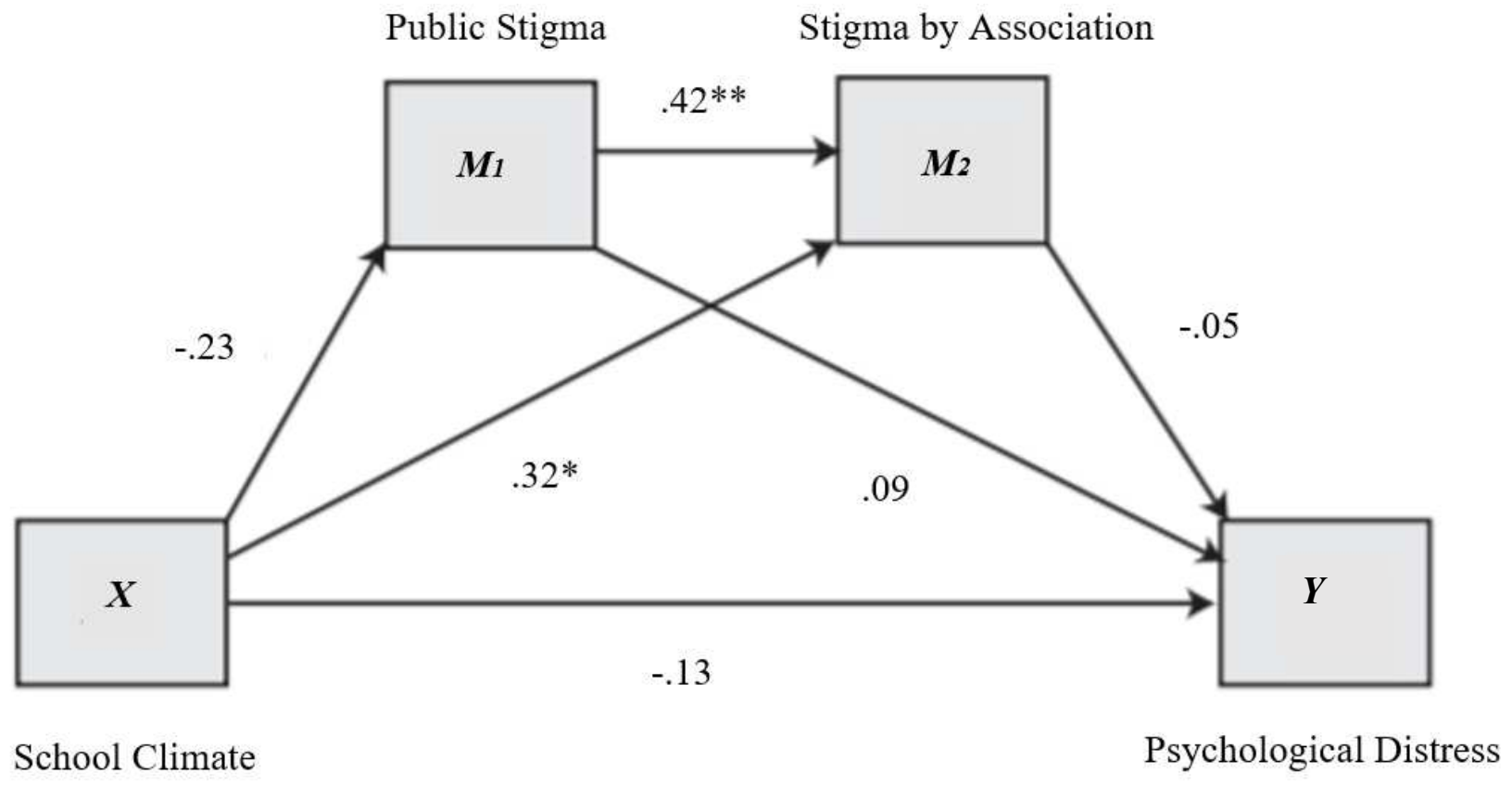


Figure B-3. Hayes process model of public stigma and stigma by association mediating school climate and social support

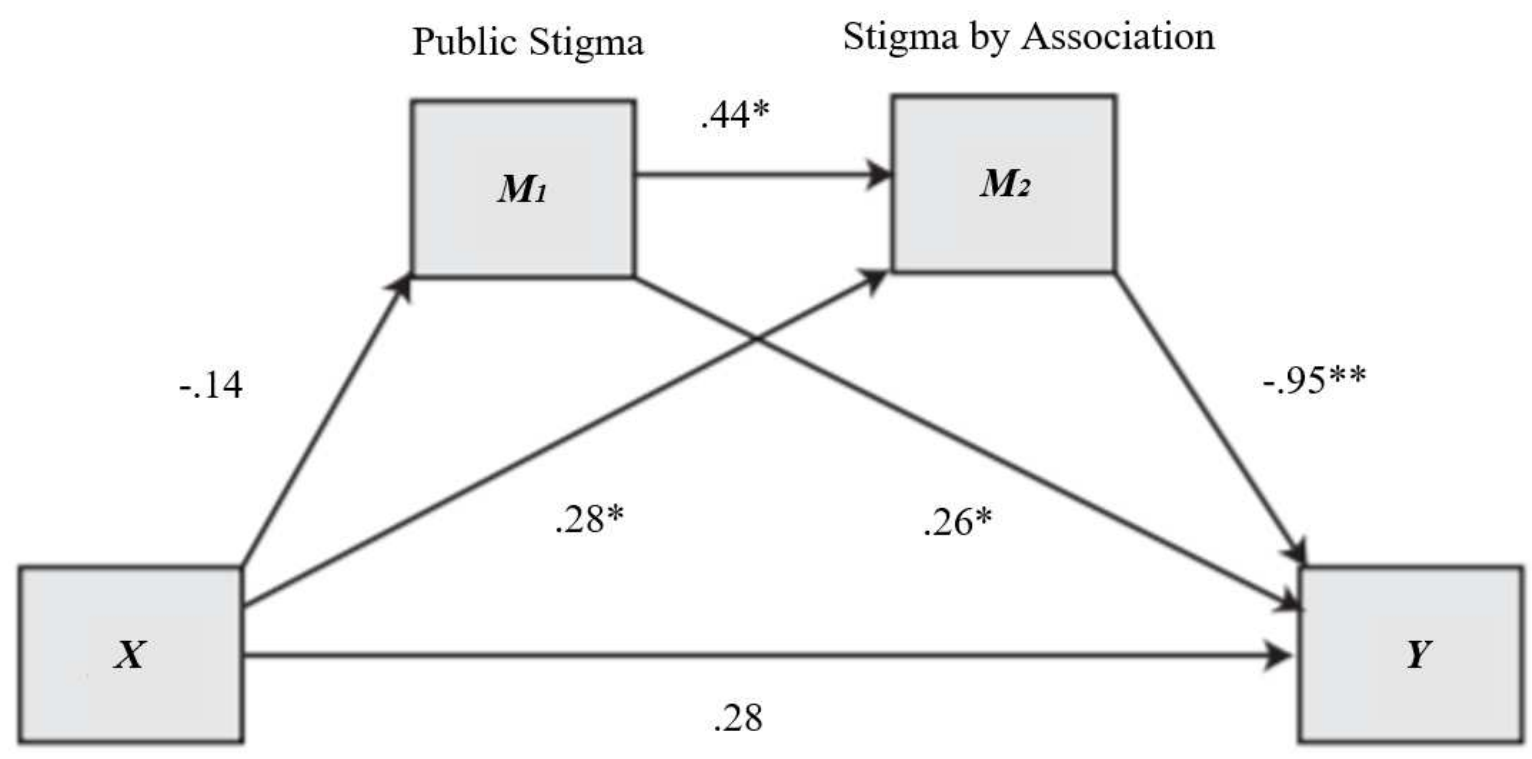

School Climate

Social Support 